\title{
TRABALHO, CLASSE TRABALHADORA E PROLETARIADO ENSAIO SOBRE AS CONTRADIÇÕES E CRISES DO CAPITALISMO CONTEMPORÂNEO
}

\author{
Adrián Sotelo V.*
}

\begin{abstract}
RESUMO:
Este artigo discute de forma concisa conceitos chaves do modo de produção capitalista, a partir de $O$ Capital de Karl Marx. Parte-se da premissa que há em $O$ Capital uma unidade lógica, senão dialética, para compreender suas categorias, conceitos e suas leis fundamentais, para relacioná-las com o processo histórico-social do modo de produção capitalista. Desta forma, confronta-se $O$ Capital em uma perspectiva de totalidade com a tese e concepções desenvolvidas por Ségio Lessa, demonstrando seu caráter sumamente, débil e carente de elementos de demonstração, pois incapaz de pensar a obra marxiana em sua unidade e totalidade. Expõe-se a profundidade das categorias de $O$ Capital sobre o processo de exploração do capital sobre o trabalho, visando recolocar o problema do trabalho produtivo e improdutivo, manual e intelectual, concreto e abstrato nos verdadeiros sentidos marxianos.
\end{abstract}

Palavras-chave: O Capital, Trabalho, Mais-Valia

\section{WORK, WORKING CLASS AND WORKERS TEST ON CONTRADICTIONS AND CRISIS OF CONTEMPORARY CAPITALISM}

\begin{abstract}
:
This article argues of concise form concepts keys in the way of capitalist production, from The Capital of Karl Marx. It has been broken of the premise that has in The Capital a logical unit, senão dialectic, to understand its categories, concepts and its laws basic, to relate them with the description-social process in the way of capitalist production. In such a way, it is collated The Capital in a perspective of totality with the thesis and conceptions developed for Ségio Lessa, demonstrating its character utmost, weak and devoid of elements of demonstration, therefore incapable to think the marxiana workmanship about its unit and totality. Depth of the categories is exposed it of The Capital on the process of exploration of the capital on the work, aiming at to recolocar the problem of productive and unproductive, manual and intellectual the work, concrete and abstract in the true marxianos directions.
\end{abstract}

Key-words: The Capital, Work, More-Value

\section{Introdução}

O presente ensaio é um trabalho polêmico: pretende discutir conceitos chaves como trabalho, força de trabalho, proletariado, classe operária, trabalho produtivo e improdutivo, lei do valor, mais-valia e exploração como categorias substanciais do modo capitalista de produção, a partir de $O$ Capital de Marx e de outros textos importantes dos fundadores do marxismo científico.

Paralelamente polemiza com algumas das teses levantadas ao redor destes temas por Sérgio Lessa em um recente livro de sua autoria ${ }^{i}$ e o qual tem um duplo mérito: por um lado, abrir e resgatar a leitura de $O$ Capital e aplicar suas categorias analíticas sobre os 
temas e, por outro lado, gerar um debate urgente e necessário frente ao tormentoso vendaval ideológico impulsionado pela direita e pela socialdemocracia que nos último vinte anos vivem irradiando e impondo o chamado pensamento único do neoliberalismo e dos temas de moda da ordem capitalista através dos Estados e dos centros internacionais de poder em nossas Universidades, Academias e Institutos de Investigação.

\section{$O$ Capital visto em sua unicidade e a categoria da totalidade}

Uma particularidade na análise de $O$ Capital é, indubitavelmente, sua necessária unidade não somente lógica, senão dialética, para compreender suas categorias, conceitos e suas leis fundamentais (valor, mais-valia, renda, preços de produção e taxa de lucro: taxa media e extraordinária, e sua tendência histórico-estrutural a declinar) e para relacioná-las com o processo histórico-social do modo de produção capitalista. Em relação ao Livro Primeiro de $O$ Capital. Crítica de economia políticaii, Marx parte do estudo da circulação do capital nas duas primeiras seções - "Mercadoria e Dinheiro" e "A transformação do dinheiro em capital", respectivamente. Somente a partir da terceira seção - "Produção da mais-valia absoluta" - entra na esfera da produção propriamente dita. Aqui começa o estudo do fundamento ontológico do Ser Social (o trabalho) e a análise detalhada da produção do capital, uma vez exposta a lei do valor-trabalho no modo de produção capitalista, através do processo de exploração do trabalho pelo capital; a produção de maisvalia (absoluta e relativa) e o processo de acumulação que, junto com a teoria da colonização (capítulo XXV), encerra o Livro I.

Os dois seguintes Livros: "O processo de circulação do capital" e "O processo global da produção capitalista", respectivamente, Marx os destinará à abordagem de questões particulares e complementares expostas no primeiro Livro. Aqui cabe aclarar que independentemente de que Marx não tenha realizado a redação definitiva destes dois últimos Livros, de acordo com Marini, “... essa orientação metodológica não somente corresponde à fórmula geral do capital [D-M-D’: A. S.], senão que também da conta da transformação da produção mercantil simples em produção mercantil capitalista".iii

É assim que, enquanto o Livro II: "O processo de circulação do capital", Seção I: "As metamorfoses do capital", Marx analisa o ciclo do capital, o qual atravessa simultaneamente as esferas do capital-dinheiro, capital produtivo e capital-mercadoria (e cuja ruptura desencadeia uma crise), o livro III estuda o processo global da produção capitalista, enquanto síntese dialética e desenvolvida dos livros anteriores; no qual a esfera da circulação é vista simplesmente por Marx como processo de metamorfose das formas do valor (ocultas, fetichizadas, alienadas) e demonstra, ao mesmo tempo, que tal esfera (ou seja, o mercado) não cria valor, nem muito menos mais-valia; portanto, localizando ali as formas gerais do trabalho improdutivo e suas categorias socioeconômicas concatenadas.

Por último, também devemos assentar aqui as teses de que, se bem é certo que o Livro I de $O$ Capital é o suporte de todo o edifício da construção teórica de Marx e constitui, por assim dizer, sua argamassa, os outros dois Livros, uma vez construído e terminado o edifício, servem ao mesmo tempo de apoios fortificantes e explicativos das categorias do primeiro (mercadoria, valor, dinheiro, mais-valia, lucro) na medida em que, em planos cada vez mais concretos da análise, através deles, Marx vai analisando e expressando suas manifestações tal como se produzem na superfície da sociedade, é dizer, na forma fetichizada e alienada como o capitalismo as constrói e as reflete ideologicamente. Referindo-se aos Livros II e III de Marx, conclui Rosdolsky, “... sem o tratamento dos problemas correspondentes a seu âmbito, resultaria impossível imaginar $O$ Capital como tal". iv - 4 - 
Em suma, é assim que, por exemplo, nos proporciona Rosenberg a razão da necessidade de articular os três Livros de $O$ Capital de Marx numa visão de conjunto, quando escreve:

É aqui que reside o motivo pelo qual o estudo do modo de produção capitalista, em seu aspecto concreto, tampouco pode esgotar somente com a análise do processo de produção e do processo de circulação. Requer-se também a investigação do 'movimento real', donde 'os capitais se contrapõem um ao outro em formas concretas'. Esta investigação é o objeto do Livro III de $O$ Capital. Porém, seu complemento somente pode ser alcançado sobre a base das investigações dos primeiros Livros. ${ }^{\vee}$

Estas anotações eram necessárias para esclarecer e localizar as categorias marxistas (valor, mais-valia, lucro, trabalho, classe social, modo de produção, proletariado, revolução) em sua dimensão global, científica e crítica com o fim de compreender o capitalismo contemporâneo, tanto no modo específico de produção, quanto no mundo do trabalho de nossos dias.

\section{Classe trabalhadora, proletariado e trabalho assalariado: quem produz o valor, a mais-valia e o capital? Comentários críticos de Sérgio Lessa}

Sérgio Lessa se propõe a realizar uma "leitura imanente" do primeiro Livro de $O$ Capital de Marx ${ }^{\mathrm{vi}}$ com o fim de esclarecer três temas que considera chaves: a) a questão política relativa à que se o proletariado é, e seguirá sendo, a classe revolucionária; b) a questão ontológica: as mudanças nos processos produtivos hão provocado mutações importantes na essência das classes sociais? Por último, se pergunta: c) é o emprego, e seguirá sendo este, o determinante das "identidades sociais"?

As respostas que Lessa propõe a estas questões encontram respaldo em sua peculiar "leitura imanente", com a qual o autor conclui que somente tem valor analítico o Livro I de $O$ Capital e, segundo ele, este deve ser o "... referencial principal da leitura e interpretação de todos os outros textos...", (se refere aos livros II e III de $O$ Capital), devido a que para ele "... a versão final saiu diretamente de seu autor..."vii. Aqui cabe perguntar: não foi acaso Marx quem ideou, planejou e escreveu, com seu punho e letra, os Livros II e III de $O$ Capital, independentemente, de que tenha sido seu amigo Friedrich Engels (que contava com a confiança, a autoridade moral e teórica para fazê-lo) quem os revisou e publicou? Acaso Marx não havia elaborado, pelo menos desde os Grundrisse, um esquema geral de toda sua obra, que contemplava, além destes três volumes, outro relativo às teorias sobre a mais-valia? ${ }^{\text {viii }}$

Porém o autor se cuida de esclarecer que: "Foi por este motivo que nos fixamos, nesta investigação primeira, apenas e tão somente no Livro I de $O$ Capital. Estamos convencidos que, para um texto introdutório como este, fixar-se no Livro I é o procedimento mais seguro. Como nada nos manuscritos poderá ter prioridade exegética frente ao Livro I, é a partir do Livro I, e jamais contra ele, que devemos avançar na

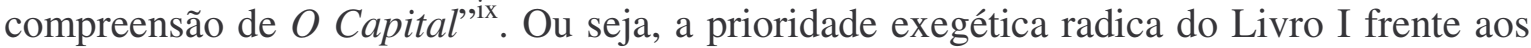
Livros II e III, no caso de que existam "discrepâncias" entre estes e aquele; entretanto, explica Lessa ${ }^{\mathrm{x}}$, estes últimos têm prioridade sobre todos os escritos elaborados por Marx e Engels entre o período que vai de 1857 a 1867 que, por ele deduzimos, devem ser tratados como peças de Museu. ${ }^{\text {xi }}$

Este modo de ler, selecionar, discriminar uma determinada obra e seus conteúdos, tem méritos relativos, porém, ao mesmo tempo, também graves implicações e riscos que 
podem conduzir a tergiversações e à parcialidade de um pensador ou de toda uma corrente de pensamento científico. E aqui radica o verdadeiro problema e limite do método estruturalista de "leitura imanente", que geralmente se aplica no campo da lingüística e da literatura.

Se entendemos por "imanência" algo inerente à coisa, que se une inseparavelmente a sua essência, então a leitura imanente pretende realizar uma fiel interpretação exegética como método de interpretação de um texto sem recorrer a "elementos externos", é dizer, contextos, dados e fatos que o podem perturbar ou alterar seus conteúdos significativos. Porém, como adverte Martín Salinas há um risco:

A análise imanente, ou mesmo análise que intente colocar a autonomia da obra no centro desde o qual emerge o valor, não pode realizar-se senão sobre a consciência de seu caráter processual; do contrário, o pretendido imanentismo se apegará de tal modo ao imediatismo manifesto na obra, que impossibilitará a compreensão do que esta contém como totalidade. Assim as contradições não serão senão o ponto de partida no qual o caráter processual da obra se desenvolve, sem apologéticas atenuações ${ }^{\text {xii }}$

Uma vez escolhido o Livro I do Capital como eixo da "leitura imanente", este Livro se reduz, injustificadamente, ao capítulo V: "Processo de Trabalho e processo de valorização" correspondente à Seção III: "A produção da mais-valia absoluta"; e ao capítulo XIV: "Mais-valia absoluta e relativa" que corresponde à Seção V: "A produção da mais-valia absoluta e relativa" deste mesmo livro.

Como resultado se esboça as seguintes considerações:

a) O trabalho é a categoria fundante do mundo dos homens.

b) O proletariado é o único que realiza um trabalho manual (nem intelectual, nem improdutivo), porque transforma a natureza e produz a mais-valia. ${ }^{\text {xiii }}$

c) Pode-se interpretar que para Lessa o trabalho intelectual, imaterial, o conhecimento e seus agentes sociais têm que colocar-se no lado do trabalho improdutivo $^{\text {xiv }}$ ainda que produzam mais-valia, pela simples razão de que não intervêm na transformação da natureza, portanto, na sua conversão em meios de produção e de subsistência. O que, pelo contrário, ocorre somente com o trabalho produtivo manual do proletário.

d) Os trabalhadores assalariados em geral (que podem produzir ou não maisvalia) não pertencem à classe proletária, no sentido que Lessa confere a este conceito (a qual, por certo, vem representando cada vez mais uma minoria da força de trabalho dentro do total mundial), e vivem indiretamente da riqueza produzida pelo trabalho proletário.

e) Esses trabalhadores assalariados não-proletários pertencem à "porção parasitaria da sociedade".

f) Por tudo que foi dito anteriormente, o "proletariado" é a única classe revolucionária da sociedade capitalista que é capaz de superá-la.

g) A diminuição quantitativa dos "postos de trabalho" dos proletários que transformam a natureza (?) não deve ser interpretada como perda do potencial revolucionário dessa classe, porque é um equívoco pensar que, para realizar a revolução, é necessária a participação, senão da maioria, pelo menos de uma significativa parcela da população.

Este livro aborda estas temáticas, porém, através de uma leitura, a nosso juízo, muito parcial de $O$ Capital, na qual são desdenhados os textos fundamentais dos criadores 
do marxismo científico. Limita-se, em suma, aos capítulos V e XIV do Livro I, sem abordar os Livros II e III de $O$ Capital e, por suposto, também o Capítulo VI - Inédito.

\section{Uma peculiar leitura de $O$ Capital}

A tese central do livro de Lessa é, sumamente, débil e carente de elementos de demonstração: somente o "proletariado" (que nunca define com precisão) cria mais-valia e "transforma a natureza", produz meios de produção e de subsistência (setores I e II nos esquemas de reprodução de Marx na terceira seção do Livro II). Desta maneira, confunde proletariado com trabalho assalariado; trabalho produtivo com improdutivo e carece de uma clara interpretação, essencial, da teoria do valor-trabalho de Marx, como veremos.

A respeito disso, Marini diz que:

... restringir a classe trabalhadora aos trabalhadores assalariados que produzem a riqueza material, é dizer, ao valor de uso sobre o qual repousa o conceito de valor, corresponde a perder de vista o processo global da reprodução capitalista. Como o destaca repetidamente Marx, o desenvolvimento da produção mercantil capitalista não faz senão acrescentar o número de trabalhadores assalariados e, portanto, dos trabalhadores involucrados no processo de reprodução, sem que isto implique, nem muito menos, como se há pretendido, que Marx considere uma sociedade formada exclusivamente por capitalistas e trabalhadores. Deste ponto de vista estritamente econômico, a tendência do sistema é aumentar, nunca de diminuir, a classe trabalhadora, é dizer, aquela categoria social formada por trabalhadores pagos mediante a inversão de capital variável e cuja remuneração é sempre inferior ao valor do produto de seu trabalho. Se, por um lado, devido ao aumento da produtividade do trabalho, tende a reduzir a quantidade de trabalhadores ligados diretamente à produção, se incrementa, por outro lado, o número dos que se empregam nas esferas da circulação e da distribuição. Trabalho produtivo e improdutivo são, pois, conceitos historicamente determinados, referidos às atividades que contribuem para valorizar ou fazer rentável o capital. ${ }^{\mathrm{xv}}$

Esta definição do trabalho produtivo relacionado com o trabalho improdutivo na produção global de valor, de mais-valia e de capital, coincide com as teses de Antunes na seguinte passagem:

De fato, se trata de um processo de organização do trabalho cuja finalidade essencial, real, é a intensificação das condições de exploração da força de trabalho, reduzindo muito ou eliminando tanto o trabalho improdutivo, que não cria valor, quanto suas formas assimiladas, especialmente nas atividades de manutenção, acompanhamento e inspeção de qualidade, funções que passaram a ser diretamente incorporadas ao trabalhador produtivo. ${ }^{\mathrm{xvi}}$

Ruy Mauro Marini diz: “... a definição alcançada por Marx no Livro I, capítulo $\mathrm{XIV}$, a respeito de que '... dentro do capitalismo, somente é produtivo o trabalhador que produz mais-valia ou que trabalha para fazer rentável o capital' (I, p.426), da conta perfeitamente do conjunto do problema e contém ainda em embrião os desdobramentos de que será objeto. Estes começam a aparecer no Livro II, capítulo VI, quando Marx distingue 
trabalho produtivo e trabalho necessário ou socialmente útil". Mais adiante agrega Marini: "A questão do trabalho produtivo, embora claramente estabelecida desde o Livro I, como destacamos, somente ficará completamente resolvida no capítulo XVII do Livro III, ao se estudar os trabalhadores assalariados mercantis. A pedra de toque aqui é a distinção entre capital social e capital individual. Depois de estabelecer que sua situação não se distingue da que rege o conjunto da classe trabalhadora, Marx se dedicará a explicar como os trabalhadores comerciais '... produzem diretamente lucro, embora não produzam diretamente mais-valia (da qual lucro não é mais que uma forma transfigurada)' (p. 286). E a explicação não podia ser mais simples: 'Do mesmo modo que o trabalho não-pago do trabalhador cria diretamente mais-valia para o capital produtivo, o trabalho não-pago dos trabalhadores assalariados comerciais cria para o capital comercial uma participação naquela mais-valia' (Livro III, p.287). O mesmo vale para os demais trabalhadores da circulação naquelas atividades indispensáveis para que esta tenha curso (banco, publicidade, etc.). Por ali ficam, sem embargo, naturalmente excluídos os trabalhadores assalariados cuja remuneração corresponde simplesmente a gastos da mais-valia, como o empregado doméstico, o burocrata, os membros do aparelho repressivo do Estado, por muito necessário que sejam ao capital e ao regime político que a ele corresponde". xvii

No Livro III, Capítulo XVII relativo ao "O lucro comercial"xviii, Marx se ocupa dos trabalhadores comerciais que são contratados assalariadamente pelo capitalista comercial e estabelece que:

1) São trabalhadores assalariados como qualquer outro, pois: a) o comerciante compra seu trabalho para valorizar o capital desembolsado por ele; b) o valor da FT e seu salário estão determinados pelo custo de produção $(\mathrm{V}+\mathrm{M})$.

2) Não criam mais-valia $(M)$, porém contribuem para que o capital comercial se aproprie de parte da mais-valia industrial gerada no processo de produção.

Marx conclui que, assim como os gastos de circulação do comerciante são sua fonte de lucro, a inversão que este realiza nestes gastos de circulação é uma inversão produtiva; portanto, o trabalho comercial dos trabalhadores assalariados contratados por ele, é um trabalho produtivo, porque contribui para a realização do lucro comercial. ${ }^{\text {xix }}$ Desta forma, se todo trabalho produtivo cria valor, mais-valia e, como propõe Lessa, transforma a natureza, então o trabalho produtivo do trabalhador mercantil também cobre esta característica? A resposta é sim, desde que adotemos o ponto de vista do trabalhador coletivo, e não a perspectiva do trabalhador individual.

Em síntese, consideramos que a classe operária industrial constitui o núcleo duro não somente da classe trabalhadora em seu conjunto, mas que dela também fazem parte os trabalhadores que pertencem tanto aos ramos e setores da produção, quanto os das esferas da circulação do capital, ou seja, o proletariado em sua acepção ampla.

Com base nos resultados que se inferem de uma leitura articulada dos três Livros de $O$ Capital, consideramos que o sujeito assalariado que: a) vende sua força de trabalho (manual e cognoscitiva) ao capital e é explorado por este; b) transforma a natureza através do uso dos meios de produção, c) produz meios de produção e de consumo, d) cria a maisvalia e, e) aumenta a acumulação de capital, definitivamente, pertence à classe trabalhadora.

Em acréscimo, em função de uma leitura do Manifesto do Partido Comunista - e aqui não faço outra coisa mais que apartar-me do método de "leitura imanente" - essa mesma classe operária industrial constitui também o núcleo duro do proletariado, no sentido mais amplo que Marx e Engels dão a entender neste texto, quando asseguram que o proletariado é uma categoria política formada pelos desprendimentos e pauperizações de todas as classes da sociedade burguesa: a denominam "classe explorada e oprimida", e a 
definem assim: “... o proletariado, essa classe operária moderna... o proletariado se recruta dentre todas as classes da população...”. xx

Há autores, para quem proletariado é sinônimo de classe dos trabalhadores assalariados, classe social dos vendedores da força de trabalho ${ }^{\text {xxi }}$, que compõem a totalidade viva do trabalho, objeto de exploração, espoliação e expropriação do capital, e se inserem em uma multiplicidade de atividades que vão desde a produção, a circulação e, incluso, o consumo de mercadorias, até a administração pública. ${ }^{\text {xxii }}$

Antunes também utiliza como sinônimos proletariado e "classe trabalhadora", a classe "que vive do trabalho", como se pode perceber na seguinte passagem:

“... eu diria, então, para começar a fazer um desenho desta problemática, que o proletariado ou a classe trabalhadora hoje, ou o que denominei a classe-que-vive-do-trabalho compreende à totalidade dos assalariados, homens e mulheres que vivem da venda da sua força de trabalho e que são despossuídos dos meios de produção. Essa definição marxiana $\mathrm{e}$ marxista me parece inteiramente pertinente, como de resto o conjunto essencial da formulação de Marx, para se pensar a classe trabalhadora hoje". xxiii

De qualquer forma, estas denominações conceituais dão conta das mudanças operadas no último meio século, tanto na estrutura de classes do capitalismo mundial, como na estrutura particular da classe operária e, em geral, das classes exploradas e oprimidas da sociedade (proletariado ampliado pela incursão a suas fileiras, de grandes frações da população oprimida e explorada pelo capital e pelo Estado).

Porém, quem não parece haver verificado ditas mudanças estruturais nos últimos 150 anos é Sérgio Lessa, quando aborda a questão da identificação do sujeito produtivo, criador da riqueza material e da mais-valia, o "proletariado", que entende como "... os assalariados que operam a transformação da natureza, que produzem o "conteúdo material da riqueza', que 'produzem e valorizam' o capital". ${ }^{x i v}$ Segundo seus cálculos ${ }^{\mathrm{xxv}}$ estes proletários não ultrapassam $20 \%$ da força de trabalho empregada na transformação da natureza nos "países mais desenvolvidos" (?) e, apesar de que estão diminuindo no mundo, isto não implica, sustenta, a diminuição de sua "potencialidade revolucionária",xxvi , questão sobre a qual voltaremos mais adiante.

Assim, os proletários se diferenciam dos "outros assalariados", que não são proletários, sempre segundo o autor, simplesmente porque "produzindo ou não mais-valia, vivem indiretamente da riqueza produzida pelo trabalho proletário". xxvii Tese muito discutível porque aqui o autor confunde, entre outras coisas, trabalho abstrato com trabalho concreto, útil, da força de trabalho. Quando faz a “... distinção entre trabalho e trabalho abstrato (o conteúdo material da riqueza social é produzido pelo trabalho" - (?) - e afirma que: “... a mais-valia é produzida pelo trabalho abstrato" (Lessa, pág. 347), comete o erro de atribuir a produção de mais-valia ao trabalho abstrato, não compreendendo com Marx, pelo contrário, a essência da lei do valor-trabalho: o trabalho abstrato, determinado pelo tempo socialmente necessário para a produção da mercadoria $(\mathrm{C}+\mathrm{V}+\mathrm{M})$, é o que determina o valor desta, embora o valor de uso da mercadoria força de trabalho-capital variável (V), que o capitalista compra no mercado de trabalho, é o que produz e determina a magnitude da mais-valia $(\mathrm{M})$ de que se apropria o capital $^{\mathrm{xxviii}}$. Aplicando isto temos: o valor da mercadoria força de trabalho do proletariado, assim como o valor da força de trabalho de outros trabalhadores assalariados e o valor de qualquer outra mercadoria, está determinado pelo tempo de trabalho, social, abstrato, e seu valor de uso é o que produz a mais-valia. 
A explicação de Marx é a seguinte: $\mathrm{O}$ valor de uso da força de trabalho ${ }^{\mathrm{xxix}}$ é a fonte de valor (Marx, L. I, capítulo 4, pág. 126). "O processo de consumo da força de trabalho é, ao mesmo tempo, o processo de produção da mercadoria e da mais-valia". " Asxim, Marx distingue o valor da força de trabalho de sua valorização no processo de trabalho, posto que “... são, portanto, dois fatores completamente distintos, Ao comprar a força de trabalho, o capitalista não perdia de vista esta diferença de valor. O caráter útil da força de trabalho, enquanto apta para fabricar fios ou botas, é conditio sine qua non, toda a vez que o trabalho, para poder criar valor, há de investir-se sempre em forma útil. Porém, o fato decisivo é o valor de uso específico desta mercadoria, que o permite ser fonte de valor, e de mais valor (grifos meus) que ela mesma tem... Em efeito, o vendedor da força de trabalho, igualmente como com qualquer outra mercadoria, realiza seu valor de troca $e$ aliena seu valor de uso. Não pode obter o primeiro sem desprender-se do segundo". xxxi

A importância desta discussão radica-se no fato de que para Lessa a distinção entre trabalho (que não define a que tipo se refere) e trabalho abstrato constitui, assim diz ele, o "fundamento objetivo da distinção entre proletariado e assalariados em geral". xxxii

Perguntamos: o valor de uso da força de trabalho, que os proletários e os trabalhadores assalariados vendem ao capitalista, se determina ou não de acordo com a lei do valor, é dizer, pelo trabalho abstrato? Ambos os tipos de trabalhadores ao vender-alienar o valor de uso, ou seja, seu trabalho concreto ao capital, não são explorados por este? Se ambos os tipos de trabalhadores vendem o valor de uso de sua mercadoria força de trabalho, e são explorados pelo capital, acaso não têm o potencial produtivo para produzir mais-valia?

Aqui é discutível o fator determinante que, segundo o autor, distingue o proletariado de outros assalariados, a saber, que o proletariado é o único que produz o conteúdo material da riqueza ${ }^{x x i i i}$, enquanto os outros, no melhor dos casos, somente produzem mais-valia. Sem embargo, há que reiterar que o elemento essencial que marca o fundamento objetivo da distinção entre proletariado e trabalhadores assalariados em geral não é, como sustenta Lessa, a "transformação da natureza" e a "produção do conteúdo material da riqueza" que, devemos esclarecer, no capitalismo, ambas as atividades se desenvolvem sobre a lógica do capital e por intermediação dos meios de produção e do sistema de máquinas que são propriedade privada do capital. A suposição que define "proletário" a partir do "trabalho que transforma a natureza e produz o conteúdo material da riqueza" (atividades comuns, segundo Marx, a todas as sociedades humanas devido a que é trabalho em geral, o qual é a sustentação ontológica do ser social) ${ }^{\mathrm{xxxiv}}$ não é válida porque no modo capitalista de produção o trabalho fica completamente subordinado ao capital e a sua lógica de produção de mais-valia: subsunção real do trabalho ao capital.

Portanto, do anterior podemos enunciar, baseados na leitura dos três Livros de $O$ Capital de Marx, que todo trabalhador assalariado que produz mais-valia de maneira direta ou indireta para o capital, que é explorado por este, é um trabalhador produtivo e tem que ser colocado nas fileiras da classe trabalhadora, independentemente se esteja dentro ou fora da indústria, no campo ou na cidade, não importando, também, se realize um trabalho manual ou intelectual, mas sim que contribua para fazer o capital rentável.

Por esta razão o argumento de Lessa resulta muito perigoso quando enfrenta o "proletariado" com os "demais" trabalhadores assalariados e não assalariados em geral, produtivos e improdutivos, do campo e da cidade, quando, então, os coloca e caracteriza como a "porção parasitária da sociedade": os trabalhadores assalariados não-proletários (?), segundo Lessa, estão enquadrados juntos à burguesia, no "setor parasitário da sociedade". xxxv

Portanto, deduz-se que os trabalhadores assalariados, igualmente à burguesia, "exploram" indiretamente os proletários, pelo motivo de que vivem da parte da mais-valia 
criada por estes, através da redistribuição que efetua o capital e o Estado em forma de salários. ${ }^{\text {xxxvi }}$

\section{O trabalho intelectual e a produção de mais-valia}

Como, para Lessa, "todo trabalho coletivo tem que ser manual""xxxii , correlativamente o trabalho intelectual é, por definição, improdutivo: "Não podia, portanto, ser 'semelhante', exibir o 'cunho da continuidade', nem poderia fazer parte dos 'operários de fábrica', o trabalho intelectual que, encarregado do 'controle', se 'opõem como inimigo' ao trabalho manual". xxxviii

Aqui devemos fazer duas observações esclarecedoras. Primeiro, é diferente fazer coincidir a pessoa à sua categoria (engenheiro, técnico ou arquiteto) como encarnações do trabalho intelectual, embora o operário-proletário se personifique no trabalho manual, vivo. Aqui, como afirma Marx, o trabalho intelectual se apresenta como inimigo do trabalho manual no processo de produção. Entretanto, há outra perspectiva que se deve contemplar: a extensão do raio de ação do trabalho coletivo, que hoje é praticamente universal; $e$ dos métodos que utiliza o capital para furtar aos trabalhadores suas potências criativas, intelectuais e espirituais inerentes a sua força humana de trabalho. Esta última colocação dá razão a Simone Wolf, quando esboça a hipótese central de seu livro: "Essa hipótese é a de que a coisificação (do trabalhador) não somente permanece, senão que é qualitativamente agravada. É assim, porque as novas tecnologias da informação possibilitam operar um novo nível de apropriação e objetivação, nas máquinas e por elas, das qualidades da força de trabalho: a expropriação de suas capacidades intelectuais $e$ cognitivas" . ${ }^{\text {xxix }}$ Neste mesmo sentido é que a afirmação de Marx, de que o trabalho intelectual é inimigo do manual, transforma-se e sintetiza-se no fato de que, através da intermediação do capital, o operário-proletário se converte no seu próprio inimigo, devido a que a expropriação de seu saber-fazer-intelectual pelo capital, através de sua gerência e de seus sistemas administrativos ${ }^{\mathrm{xl}}$, se lhe apresente como inimigo, posto que esse saber expropriado se ponha ao serviço da produção da mais-valia e da "transformação da natureza", através da manipulação das máquinas, é dizer, do "trabalho morto".

Quando Lessa sustenta que o trabalho intelectual não produz mais-valia nem lucro para o capital, o faz pensando que "o trabalho intelectual não é parte do trabalhador coletivo" (p. 191), porque não pode ser produtor de mais-valia, e, portanto, não realiza trabalho produtivo, contradizendo a definição ampliada, que deste conceito faz Marx, no capítulo XIV do Livro I de $O$ Capital, quando relaciona o trabalho produtivo com o conceito de trabalhador ou operário coletivo e, assim, incluindo o trabalho intelectual. Logicamente que se aqui se concebe como "isolados", a todos os "atores" que personificam o "trabalho intelectual": engenheiros, técnicos, médicos, enfermeiras, professores de escola; então, todos são inimigos do trabalho manual, é dizer, do proletariado, como constituintes de uma classe social não-proletária, não-operária, que se enfrenta a este último como inimigo. Somente assim o argumento de Lessa tem validez. Porém as coisas não ocorrem dessa maneira.

Há uma interpretação errada do conceito de "trabalhador coletivo" que, segundo Lessa, “... não inclui a todos os trabalhadores assalariados, mas apenas aqueles que são produtivos". xli Entretanto, Marx diz outra coisa: que o trabalho produtivo é todo aquele trabalho assalariado realizado por um trabalhador (proletário ou não), que é membro do órgão do trabalhador coletivo, que executa alguma de suas múltiplas funções (manuais ou intelectuais que são atributos do trabalho vivo) e que podem estar combinadas; e, além disso, têm que produzir mais-valia para o capital ou contribuir à rentabilidade deste. 
Dentro desta perspectiva, os trabalhadores assalariados da esfera da circulação do capital - um garçom de restaurante, o chefe que prepara os alimentos, o "intelectual" explorado pela Microsoft para produzir software que rentabilizem seu capital, os milhares de trabalhadores assalariados das telecomunicações que instalam os telefones que vendem as companhias, os Moto Boys das grandes cidades brasileiras que são contratados e explorados intensamente por companhias capitalistas organizadas nessas atividades, sem mencionar os trabalhadores das grandes franquias de comida rápida do capital internacional, como McDonald's; as centenas de trabalhadores intelectuais e manuais que trabalham nos "empórios do conhecimento", como os do Vale do Silício (Silicon Valley), na zona sul da Baía de São Francisco, no norte da Califórnia, postos a produzir produtos eletrônicos de alta tecnologia nos grandes parques industriais ali instalados - todas estas categorias de trabalhadores que somam milhões e milhões por todo o planeta, em verdade, são inimigos declarados do "proletariado" como propõe o livro de Lessa?

\section{Conclusão}

As categorias de trabalhadores que temos assinalado, a nosso juízo, são parte do trabalho produtivo do trabalhador coletivo no capitalismo atual que, como diz Antunes, hoje constituem uma classe trabalhadora mais "heterogeneizada, fragmentada $e$ complexificada" "xlii e que pode ou não incorporar-se ao proletariado social nos termos do Manifesto. Porém, isso vai depender de sua consciência de classe, de sua organização política e da capacidade que o núcleo duro da classe operária industrial tenha para incorporar-los em um projeto alternativo anticapitalista e antiimperialista de transição ao socialismo. Porque há que se esclarecer, que desafortunadamente nem sempre existe uma correlação positiva e mecânica entre a base estrutural, produção de mais-valia, trabalho produtivo e improdutivo, com os níveis de consciência da classe trabalhadora e da luta de classes. Ademais, esse projeto não pode ser obra exclusiva do proletariado industrial - que no mundo atual tende a diminuir pelas mutações operadas, tanto na estrutura de acumulação e reprodução do capital, como nas das classes sociais - senão, obra da classe operária industrial (tradicional e moderna), enquanto núcleo central do proletariado, que incorpora, como diz Marx, todas as classes exploradas da moderna sociedade burguesa de nossos dias.

\section{Bibliografia}

Alves, Giovanni, O novo (e precario) mundo do trabalho, Boitempo, São Paulo, 2000.

Alves, Giovanni, Dimensões da reestruturação produtiva. Ensaios de sociologia do trabalho, Editora Praxis, Londrina, Paraná, 2007.

Antunes, Ricardo ¿Adiós al trabajo? Ensayo sobre las metamorfosis y el rol central del mundo del trabajo, Cortez Editora, Sao Paulo, 2001.

Antunes, Ricardo Los sentidos del trabajo, Ediciones Herramienta, Buenos Aires, 2005.

Lessa, Sergio, Trabalho e proletariado no capitalismo contemporâneo, Cortez Editora, São Paulo, 2007.

Marini, Ruy Mauro, Dialéctica de la dependencia, Editorial ERA, México, 1973. 
Marini, Ruy Mauro, "El concepto de trabajo productivo. Nota metodológica", internet: http://www.marini-escritos.unam.mx/023_trabajo_productivo_es.htm.

Marx, Karl El capital, Libro I, Capítulo VI (inédito). Resultados del proceso inmediato de producción. $9^{a}$ edición en castellano, editorial Siglo XXI, México, 1981.

Marx, Carlos, El capital. Crítica de la Economía Política, Editorial Fondo de Cultura Económica, México, 2000.

Marx, Karl y Federico Engels, Manifiesto del Partido Comunista, Obras Escogidas, Editorial Progreso, Moscú, s/f.

Pinto, Geraldo Augusto, A organização do trabalho no Século 20. Taylorismo, fordismo e toyotismo, Expressão Popular, 2007.

Rosdolsky, Román, Génesis y estructura de El capital de Marx. Estudios sobre los Grundrisse, Siglo XXI, México, 1978.

Rosenberg, David I., Comentarios a los tres tomos de El Capital, Vol. 3, Facultad de Economía de la UNAM, México, s/f.

Salinas, Martín, "Lukács y el concepto de decadencia", en: http://www.herramienta.com.ar/modules.php?op=modload\&name=News\&file=article \&sid $=229 \&$ mode $=$ thread $\&$ order $=0 \&$ thold $=0$

Simone Wolf, Informatização do trabalho e reificação: uma análise dos programas de qualidade total, Editora UNICAMP-EDUEL, Londrina, PR, 2005.

\footnotetext{
* Sociólogo, investigador do Centro de Estudios Latinoamericanos (CELA) da Facultad de Ciencias Políticas y Sociales de la Univesida Nacional Autónoma de México (UNAM). Agradeço a tradução e os valiosos comentários de Kleber García Teixeira (UNESP, Marília) ao presente ensaio.

${ }^{\text {i }}$ Sergio Lessa, Trabalho e proletariado no capitalismo contemporâneo, Cortez Editora, São Paulo, Brasil, 2007.

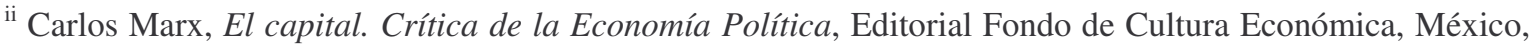
2000.

iii Ruy Mauro Marini, Dialéctica de la dependencia, Editorial ERA, México, 1973.p. 84.

${ }^{\text {iv }}$ Rosdolsky, Román, Génesis y estructura de El capital de Marx. Estudios sobre los Grundrisse, Siglo XXI, México, 1978, p. 50.

v David I., Rosenberg, Comentarios a los tres tomos de El Capital, Vol. 3, Facultad de Economía de la UNAM, México, s/f., p. 7.

${ }^{v i}$ Sergio Lessa, op. cit. Neste livro o autor se propõe “... também um segundo objetivo, mais imediatamente metodológico, que é a recuperação do significado da ortodoxia e da leitura imanente". P. 10. E mais adiante agrega: "Precisar as concepções de qualquer autor requer, de modo imperativo, da pesquisa exegética, isto é, que se conceda a mais rigorosa prioridade ao texto. E é como instrumento desta cessão (¿?) da prioridade ao texto, que se desenvolve, ao longo de séculos, o que hoje é denominado leitura imanente", p. 16/17.

${ }^{\text {vii }}$ Sergio Lessa, op. cit., p. 25.

viii Para este tema veja: Rosdolsky, op. cit.

${ }^{\text {ix }}$ Lessa, p. cit., p. 28.

${ }^{\mathrm{x}}$ Lessa, op. cit., p. 25.

${ }^{x i}$ A mesma posição tem o autor ao respeito do Capítulo VI (inédito) de Marx. Ao contrário, para nós como para outros autores, este texto é uma ponte necessária entre o Livro I e II de $O$ Capital.
} 


xii Salinas, "Lukács y el concepto de decadencia", en:

http://www.herramienta.com.ar/modules.php?op=modload\&name=News\&file=article \&sid=229\&mode=thre ad\&order $=0 \&$ thold=0. Grifos nossos. Aqui devemos considerar a interpretação de totalidade: ou uma obra, por exemplo, $O$ Capital, lê-se, em si mesma, em função de sua gênese e estrutura próprias, ou essa leitura, ademais, se realiza em função do conjunto dos textos e da formação global do pensamento de seu autor. Consideramos que esta última alternativa é a mais apropriada.

xiii Sergio Lessa, pp. 163, 169, 171, 179, 181 y 19, 211, 231, 236, 298, 312 (nesta última página não fica claro se o autor vê como idênticos o trabalho material e o trabalho manual, p. 347. É necessário esclarecer que o "proletariado" transforma a natureza, cria meios de produção e de subsistência, cria valor e mais-valia uma vez que: a) consegue vender sua força de trabalho ao capitalista em troca de uma remuneração (salário) e desencadeia o que Marx chama de o ciclo do capital-dinheiro (D...mp+ft...p.......D'); b) uma vez que o patrão o proporciona os instrumentos de trabalho e as matérias-primas (que são propriedade privada do capital) começa a trabalhar produtivamente e desencadeia o ciclo do capital produtivo (P...m...d...P'); c) por último, então, o trabalhador, que não se enfrenta romanticamente com a Natureza como se estivesse em um paraíso terreno, tem que produzir, sobre o comando do capital, meios de produção e meios de subsistência sobre a forma do capital-mercadoria (M...d...p...M) para que estas concorram no mercado, que está monopolizado também pelo capital. Este é o ciclo do capital, do modo de produção capitalista, pelo qual o trabalho assalariado está obrigado a percorrer, do início ao fim, no capitalismo de carne e osso.

xiv Afirma Lessa: "Portanto, não há qualquer justificativa para, a partir da expressão 'mais perto ou mais longe da manipulação do objeto do trabalho', postular-se que o trabalhador intelectual faria parte do trabalhador coletivo. Considerar o trabalhador intelectual como partícipe do trabalhador coletivo é um contra-senso no próprio texto marxiano" (LESSA, 2007: Pg. 190-191). Portanto se o trabalhador intelectual não está imerso no trabalhador coletivo, então, este é um trabalhador improdutivo, de acordo com o que se infere desta citação.

${ }^{\mathrm{xv}}$ Marini, Ruy Mauro, "El concepto de trabajo productivo. Nota metodológica", internet: http://www.mariniescritos.unam.mx/023_trabajo_productivo_es.htm. As referências de Marx que utiliza Marini entre parêntesis correspondem à edição de El Capital do Fondo de Cultura Económica, porém não menciona a data da edição. ${ }^{x v i}$ Antunes, Ricardo Los sentidos del trabajo, Ediciones Herramienta, Buenos Aires, 2005, p. 39. Grifos do autor.

${ }_{\text {xvii }}$ Ruy Mauro Marini, "El concepto de trabajo productivo...", op. cit.

xviii Marx, L. III, p. 286.

${ }^{x i x}$ Marx, L. III, p. 294.

${ }^{x x}$ Marx y Federico Engels, Manifiesto del Partido Comunista, Obras Escogidas, Editorial Progreso, Moscú, p. 39.

xxi Giovanni Alves, Dimensões da reestruturação produtiva. Ensaios de sociologia do trabalho, Editora Praxis, Londrina, Paraná, 2007, p. 97. Veja também seu O novo (e precário) mundo do trabalho, Boitempo, São Paulo, 2000.

xxii Alves, Dimensões, p. 98

xxiii Ricardo Antunes, Los sentidos del trabajo...op. cit., pág. 190.

xxiv Sergio Lessa, op. cit., p. 347. Veja nota 13.

${ }^{x x v}$ Lessa, p. 315.

${ }^{x x v i}$ Lessa, p. 316

xxvii Idem.

xxviii Depois de caracterizar os meios de produção como capital, Marx afirma que “... com a outra parte do dinheiro da soma adiantada, o capitalista há comprado capacidade de trabalho... trabalho vivo. Este o pertence, a igual título que as condições objetivas do processo de trabalho”, Capítulo VI Inédito, op. cit., p. 11 e na página 84 de este mesmo livro pontua: "O que constitui o valor de uso específico do trabalho produtivo para o capital não é seu caráter útil determinado, como tampouco as qualidades úteis particulares do produto no qual se objetiva, senão seu caráter de elemento criador de valor de troca (mais-valia)".

xxix Para Marx uma força de trabalho é “... o conjunto das condições físicas e espirituais que se dão na corporeidade, na personalidade viva de um homem e que este põe em ação ao produzir valores de uso de qualquer classe”, L. I, cap. IV, pág. 121.

${ }_{\mathrm{xxx}}$ Marx, L. I. cap. IV, p. 128, grifos do autor.

${ }^{\text {xxxi }}$ Marx, L. I., p. 144.

xxxii Lessa, op. cit, 347.

xxxiii Lessa, op. cit., p. 163

xxxiv Para este tema véase a György Lukács, Ontología del ser social: el Trabajo, Ediciones Herramienta, Buenos Aires, 2004. 
${ }^{x x x v}$ Sergio Lessa, pp. 198 y 207.

xxxvi Isto se contradiz com a seguinte afirmação: "Entre os proletários e os trabalhadores temos uma única identidade: são todos eles assalariados, explorados pelo capital. E, concomitantemente, distinções que não devem ser menosprezadas, pois se referem às diferentes relações que mantêm com a produção da riqueza social”, p. 184. E aqui perguntamos: para que são explorados pelo capital os trabalhadores assalariados, e o que consegue o capital mediante este processo?

xxxvii Lessa, p. 190.

xxxviii Lessa, p. 190. Grifos meus.

xxxix Simone Wolf, Informatização do trabalho e reificação: uma análise dos programas de qualidade total, Editora UNICAMP-EDUEL, Londrina, PR, 2005, p. 13.

${ }^{\mathrm{xl}}$ Como bem diz Christophe Dejours, referindo-se aos operários de fábrica na Toyota: "Eles auto-aceleramse, coletivamente, e o grupo, tomado por uma espécie de frenesi, passa a operar um poder seletivo sobre os mais lentos, 'interiorizando' assim compulsivamente as imposições organizacionais...”, cit. por Geraldo Augusto Pinto A organização do trabalho no Século 20. Taylorismo, fordismo e toyotismo, Expressão Popular, 2007, p. 91.

xli Lessa, op. cit., p. 191.

xlii Antunes, Ricardo ¿Adiós al trabajo? Ensayo sobre las metamorfosis y el rol central del mundo del trabajo, Cortez Editora, Sao Paulo, 2001, p. 164. Grifos do autor.

Artigo recebido em: 13/12/2008

Aprovado para publicação em: 15/01/2009 